\title{
Effect of the rhizosphere bacterium Pseudomonas putida, arbuscular mycorrhizal fungi and substrate composition on the growth of strawberry *
}

\author{
M Vosatka 1, M Gryndler 2*, Z Prikryl 2 \\ ${ }^{1}$ Botanical Institute, Pruhonice, near Prague, CAS; \\ 2 Institute of Microbiology, Prague, CAS, Czechoslovakia
}

(COST Meeting, 21-23 May 1992, Dijon, France)

\begin{abstract}
Summary - Micropropagated and "frigo" plants of strawberry were inoculated with arbuscular mycorrhizal fungi and with the rhizosphere bacterium $P$ seudomonas putida. An increase in growth and fruit production was observed as well as the species-specific interaction between the symbiotic fungus and the bacterium. Growth substrate composition (optimal content of commercial absorbent Zeolite) was shown to be important for a maximum growth response of inoculated plants.
\end{abstract}

strawberry / arbuscular mycorrhizal fungi / rhizosphere bacterium / Pseudomonas putida / Zeolite

Résumé - L'effet d'une bactérie de la rhizosphère, Pseudomonas putida, de champignons mycorhiziens à arbuscules et de la composition du substrat sur la croissance de fraisier. Les plantes micropropagées et ufrigo" de fraisier ont été inoculées par les champignons mycorhiziens à arbuscules et par la bactérie de la hizosphère Pseudomonas putida. L'augmentation de la croissance et la production de fruits ont été observées en même temps que l'interaction spécifique entre le champignon symbiotique et la bactérie. La composition du substrat de culture (quantité optimale de l'absorbeur commercial Zeolite) a été estimée comme très importante pour la croissance pour la plante inoculée.

fraisier / champignon mycorhizien à arbuscules / bactérie de la rhizosphère / Pseudomonas putida / Zeolite

\section{INTRODUCTION}

It has been shown that some arbuscular mycorrhizal (AM) fungal endophytes can positively affect the growth and development of strawberry (Kiernan et al, 1984; Chang, 1986). Positive growth response to mycorrhizae and increase in phosphorus uptake has also been reported by Holevas (1988). Koomen et al (1987) tested the effectiveness of mixed inocula for field inoculation of strawberry; and Hrselová et al (1987), have reported an increase in plant biomass following inoculation with Gigaspora margarita and
Glomus caledonium. However, in other experiments (Hrselova et al, 1989), an adverse effect of inoculation by Glomus $\mathrm{sp}$ was found, although in this trial an increase in runner formation by inoculated plants was observed.

The aim of the 3 experiments presented in this paper was to test suitable substrates for the transplanting and inoculation of micropropagated strawberries and also to examine the effects of separate and dual inoculation by $A M$ fungi and the rhizosphere bacterium Pseudomonas putida on the growth and fruit production of strawberry.

* Correspondence and reprints 


\section{MATERIALS AND METHODS}

\section{Experiment 1}

One-yr-old strawberry plants (so-called "frigo" plants without leaves and roots, stored over winter at low temperature) were transplanted into $500-\mathrm{ml}$ plastic pots filled with a mixture of pure commercial peat, sand (particle size $<2 \mathrm{~mm}$ ) and sterile humic garden soil $(1: 1: 1, v: v: v)$. Plants were inoculated with $1 \mathrm{~g}$ of soil obtained from either pot cultures of Glomus mosseae (Rothamsted, UK) or Glomus etunicatum (Univ Florida, Gainesville, FL). Bacterial treatments were inoculated with AM inocula together with $1 \mathrm{ml}$ of $P$ seudomonas putida suspension containing $5.10^{8}$ cells mi1 (strain $\mathrm{K} 11$ from The Institute of Microbiology, Prague, Czechoslovakia, cultivated on Taylor III medium for $48 \mathrm{~h}$ ). Each treatment consisted of 16 replicates. The plants were grown for $14 \mathrm{wk}$ in the greenhouse and watered 3 times a week. The starting level of nutrients in the substrate was $13 \mathrm{mg} \cdot \mathrm{kg}^{-1} \mathrm{P}$ and 47 mg. $\mathrm{kg}^{-1} \mathrm{~N}$. $3.5 \mathrm{mg} \mathrm{P}$ and $13 \mathrm{mg} \mathrm{N}$ were added to each pot at the beginning of the 2nd and 3rd month. Following the harvest, plants were dried at $105^{\circ} \mathrm{C}$ and the dry weight of shoots and roots assessed. The roots were stained according to Phillips and Hayman (1971), and mycorrhizal infection was determined by a grid-line intersect method (Giovannetti and Mosse, 1981). Data were analysed by Duncan's multiple range test, $P=0.05$.

\section{Experiment 2}

The seedlings and methods of cultivation and treatment were as for Experiment 1 except that the plants were cultivated for only 3 months before the number of flower stolons, flowers and also fruit weight were determined. The following symbols indicate the micro- organisms used for inoculation: K11 = Pseudomonas putida, $\mathrm{LABD}=$ Glomus albidum, $\mathrm{LAGR}=$ G aggregatum, LCLD = $G$ caledonium, LDST $=G$ deserticola, LFSC $=G$ fasciculatum, LINR $=G$ intraradices, LMSS $=G$ mosseae, $L V S F=G$ versiforme, $L T N U=G$ tenuis, $\mathrm{CHTG}=$ Scutellospora heterogama, GMGR = Gigaspora margaria and $\mathrm{CON}=$ control without inoculation.

\section{Experiment 3}

At the beginning of the experiment, 180 micropropagated plants of Fragaria ananassa cv Senga sengana were transplanted into $500-\mathrm{ml}$ plastic pots and grown in the greenhouse for 4 months. The basic cultivation substrate was a perlite-sand-peat mixture (1:1:1, v:v:v). The substrate was used with or without Zeolite (mineral absorbent). Ratios of substrate to Zeolite were $3: 1,2: 1,1: 1$ or pure Zeolite as alone was used. All the substrates were sterilized 3 times for $3 \mathrm{~h}$ at $80^{\circ} \mathrm{C}$ with $12-\mathrm{h}$ interval. Plants were inoculated with 2 $\mathrm{g}$ of soil inoculum of Gigaspora margarita (isolate from Rothamsted) and cultured for 4 months on maize. Control plants were inoculated with the same amounts of inoculum, previously sterilized by $\gamma$-irradiation $1 \mathrm{Mrad}$. After harvesting the plants, the same assessments were carried out as in Experiment 1.

\section{RESULTS}

\section{Experiment 1}

Plant shoot dry weight, unlike dry root weight, was significantly increased following inoculation with both fungal strains (fig 1). The inoculation of plants with AM fungi always caused the mycorrhizal infection (see table I, Exp 1). The com-

Table I. Mycorrhizal infection in the roots of strawberry inoculated with Glomus mosseae, G etunicatum and Pseudomonas putida (K11) in Exp 1 and in the roots of strawberry grown in different substrates with Zeolite addition inoculated with Gigaspora margarita (Exp 3).

\begin{tabular}{|c|c|c|c|c|c|}
\hline \multicolumn{3}{|c|}{ Exp 1} & \multicolumn{3}{|c|}{ Exp 3} \\
\hline Treatment & Root length infected (\%) & $S D$ & Treatment & Root length infected (\%) & $S D$ \\
\hline Control & 0 & 0 & Substrate (S) & 5.3 & 2.7 \\
\hline G mosseae & 13.0 & 4.1 & Zeolite $(\mathrm{Z})$ & 4.3 & 3.9 \\
\hline G etunicatum & 22.7 & 9.3 & $S: Z-1: 1$ & 24.2 & 10.2 \\
\hline Control + $\mathrm{K} 11$ & 0 & 0 & $S: Z-2: 1$ & 16.9 & 8.1 \\
\hline$G$ moss $+\mathrm{K} 11$ & 9.7 & 2.1 & $S: Z-3: 1$ & 9.5 & 6.1 \\
\hline Getun + K11 & 26.2 & 8.2 & & & \\
\hline
\end{tabular}




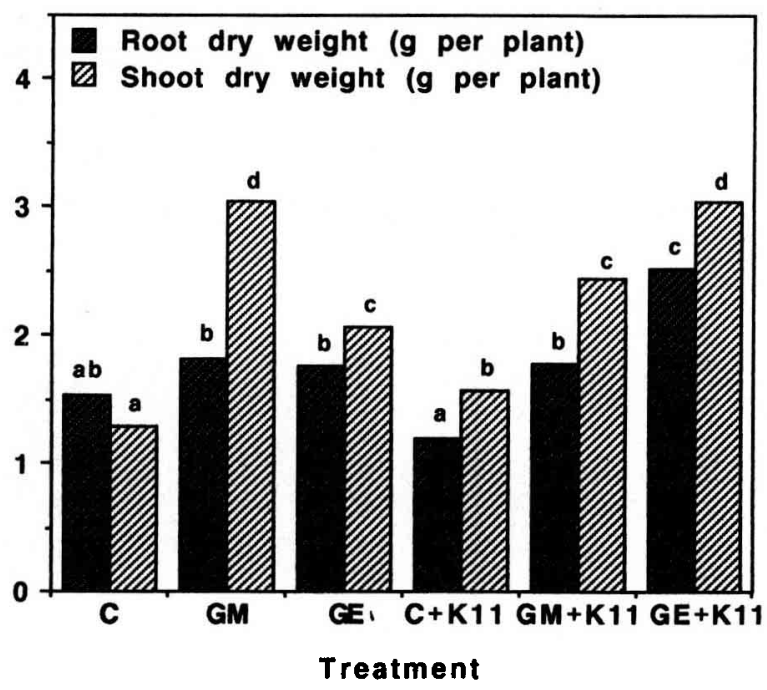

Fig 1. Effect of AM fungi (C: control; GM: Glomus mosseae; GE: Glomus etunicatum) and bacterial inoculation (K11: Pseudomonas putida) on the growth of strawberry (Exp 1).

bined inoculation with Pseudomonas putida and Glomus etunicatum resulted in a significant response by both roots and shoots, whereas an additional effect of bacteria and Glomus mosseae was apparent only on the shoot biomass.

\section{Experiment 2}

Neither the numbers of flower stolons nor fruits were significantly influenced by fungal or bacterial inoculation (table II). The yield of fruits was increased significantly (up to $40 \%$ when compared to the control) following inoculation with most of the fungal endophytes. There was no significant additional effect of dual inoculation on the mycorrhizal infection or on fruit production. In fact, the effect of the bacterial inoculation when combined with some of the fungal edophytes proved to be negative.

\section{Experiment 3}

There was no significant difference between the root or shoot biomass of uninoculated plants. A decrease in shoot biomass was observed only on plants cultured in pure Zeolite (fig 2). Best growth was found when the substrate treated with added Zeolite at a ratio of 2:1 was used. There was no significant difference between runner formation of uninoculated plants when grown in different substrates (fig 3). Inoculated plants (for infection lev-

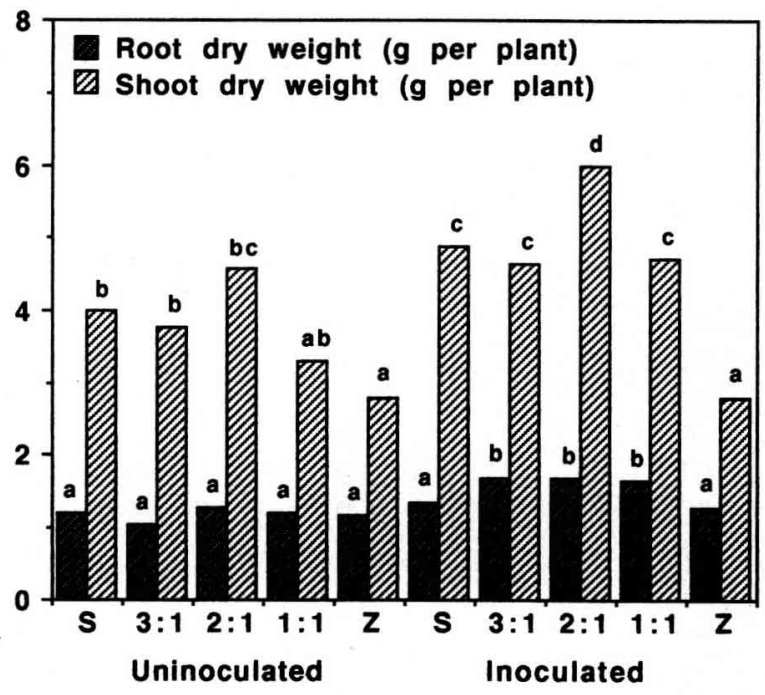

Fig 2. Effect of inoculation with Gigaspora margarita and substrate composition (S: substrate peat-perlite-sand 1:1:1, amended by mineral absorbent Zeolite at the ratio substrate:Zeolite $3: 1,2: 1,1: 1, Z$ : pure Zeolite) on the plant growth (Exp 3).

els see table I, Exp 3) produced more runners when grown in both basic substrate alone and that with Zeolite at the ratio 2:1. Fruit production of uninoculated plants was enhanced by the addition of Zeolite (3:1 and 2:1), while inoculated plants had the highest fruit production with the substrate:zeolite ratio $3: 1$. Therefore while a small amount of Zeolite could be stimulatory for the growth of both uninoculated and inoculated plants, the lowest fruit production was observed with plants growth in pure Zeolite cultures.

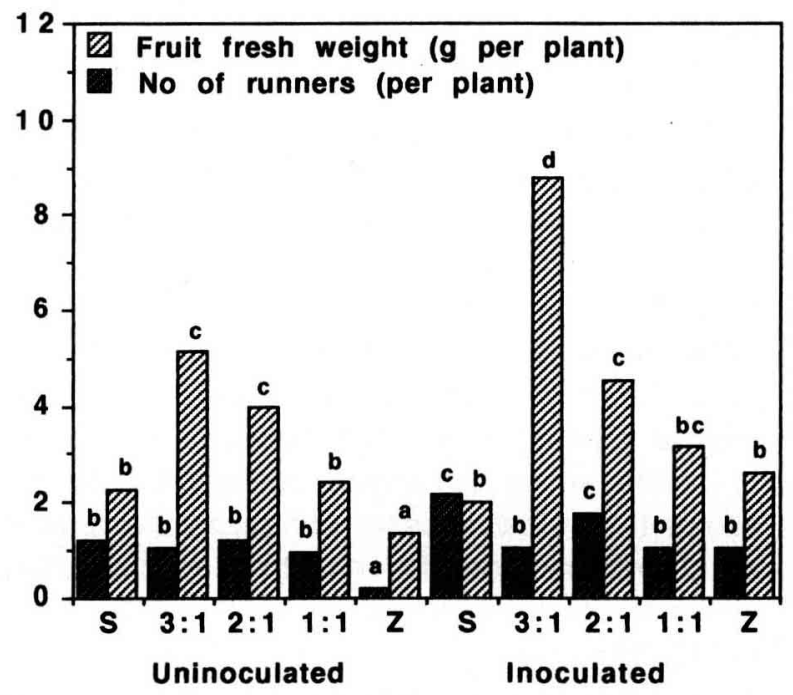

Fig 3. Effect of inoculation with Gigaspora margarita and substrate composition on the runner and fruit production (Exp 3). For explanation of treatments see figure 2. 
Table II. Effect of inoculation of strawberries by AM fungi and bacterium Pseudomonas putida on the number of flower stolons per plant, number of flowers per plant, fruit weight per plant and on shoot and root biomass (Exp 2). For explanation of treatments see Materials and Methods.

\begin{tabular}{|c|c|c|c|c|c|}
\hline Treatment & No of flower stolons & No of flowers & Fruit weight $(g)$ & Root length infected (\%) & $S D$ \\
\hline CON & 1.0 & 7.1 & 26.1 & 1.1 & 4.9 \\
\hline LABD & 0.9 & 6.9 & 31.5 & 5.5 & 4.6 \\
\hline LAGR & 1.0 & 5.7 & 32.0 & 11.2 & 7.9 \\
\hline LCLD & 0.9 & 7.0 & 32.8 & 9.2 & 5.7 \\
\hline LDST & 0.9 & 4.8 & 27.8 & 4.6 & 5.8 \\
\hline LFSC & 1.2 & 8.8 & 37.5 & 10.5 & 6.8 \\
\hline LINR & 1.0 & 8.6 & 33.6 & 15.8 & 7.2 \\
\hline LMSS & 1.0 & 6.0 & 22.0 & 15.2 & 6.3 \\
\hline LVSF & 1.0 & 9.6 & 37.4 & 20.4 & 10.2 \\
\hline LTNU & 1.0 & 7.3 & 33.3 & 10.8 & 4.9 \\
\hline CHTG & 1.0 & 10.4 & 29.7 & 2.2 & 3.4 \\
\hline GMGR & 1.1 & 9.9 & 34.3 & 18.6 & 6.2 \\
\hline $\mathrm{CON}+\mathrm{K} 11$ & 0.7 & 4.8 & 23.6 & 0.0 & 0.0 \\
\hline $\mathrm{LABD}+\mathrm{K} 11$ & 1.0 & 7.9 & 35.8 & 20.1 & 3.6 \\
\hline$L A G R+K 11$ & 1.2 & 5.5 & 27.0 & 4.8 & 5.2 \\
\hline LCLD + K11 & 1.3 & 10.0 & 36.9 & 20.5 & 6.8 \\
\hline LDST + K11 & 0.8 & 5.5 & 33.3 & 10.2 & 4.2 \\
\hline LFSC $+\mathrm{K} 11$ & 0.8 & 5.7 & 32.0 & 15.1 & 9.2 \\
\hline LINR + K11 & 1.0 & 6.8 & 29.5 & 45.2 & 15.6 \\
\hline LMSS + K11 & 1.0 & 9.9 & 30.8 & 16.9 & 8.6 \\
\hline LVSF + K11 & 0.9 & 9.1 & 40.4 & 38.2 & 12.8 \\
\hline LTNU + K11 & 0.5 & 2.5 & 19.4 & 5.6 & 3.9 \\
\hline CHTG + K11 & 0.7 & 5.1 & 25.9 & 5.6 & 2.5 \\
\hline $\mathrm{CMRG}+\mathrm{K} 11$ & 0.9 & 7.0 & 36.4 & 26.5 & 10.6 \\
\hline LSD 0.05 & & 4.4 & 7.1 & & \\
\hline
\end{tabular}

SD represents standard deviation of percentage root length infected.

\section{DISCUSSION}

The increase of plant growth and fruit production, observed in all experiments following the inoculation of plants with AM fungi confirms findings of other authors (Holevas, 1988; Kiernan et $a l, 1984)$. The effects of bacterial inoculation are rather controversial, and only in combination with some fungi was there an additional positive response with Pseudomonas putida. The addition of Zeolite, which can absorb some nutrients and allows their slow release, enhances the growth of strawberry and the effect of mycorrhizae. These findings agree with the results of Vestberg (1992; this volume) who found the positive effect of controlled release fertilizer Osmocote on the development of mycorrhizae and growth response of strawberry. In agreement with obser- vations of Hrselova et al (1989), we found a significant increase in runner production of inoculated plants grown in 2 different substrates.

If commercially used growth substrates contain moderate amounts of phosphorus, inoculation with most of the AM fungal endophytes and Pseudomonas putida could be beneficial for the growth and fruit production of strawberry. Howev$e r$, it is necessary to find the most effective strains because, as was shown here (and also reported by Lin et al, 1987), some AM endophytes may not be beneficial for plant growth.

\section{ACKNOWLEDGMENTS}

We thank our colleague IA Vít for his assistance and $J$ Rouckova and $J$ Husnerova for technical help. 


\section{REFERENCES}

Chang DCN (1986) Response of micropropagated (cultivar) Harunoka strawberry (Fragaria ananassa) to Glomus endomycorrhizal fungi. Hortsci 21, 885

Giovannetti M, Mosse B (1980) An evaluation of techniques for measuring vesicular-arbuscular mycorrhizal infection of roots. New Phytol 80, 1-12

Holevas CD (1988) The effect of vesicular-arbuscular mycorrhiza on the uptake of soil phosphorus by strawberry (Fragaria $\mathrm{sp}$ var Cambridge Favourite). J Hortic Sci 41, 57-64

Hrselova H, Gryndler M, Vancura V (1989) Influence of inoculation with VA mycorrhizal fungus Glomus sp on growth of strawberries and runner formation. $\mathrm{Ag}$ ric Ecosyst Environ 29, 193-197

Ḣrselova $H$, Vejsadova $H$, Prikryl Z, Vachova J, Vancura $V$, Vit A (1989) Effect of inoculation with vesicular-arbuscular mycorrhizal fungi on growth of strawberries. In: Interrelationships Between Plants and
Microorganisms in Soil (Vancura V, Kunc F, eds) Academia, Prague, 109-114

Kiernan JM, Hendrix JW, Stolz LP, Maronek DM (1984) Characterization of strawberry plants produced by tissue culture and infected with specific mycorrhizal fungi. Hortsci 19, 883-888

Koomen I, Grace C, Hayman DS (1987) Effectiveness of single and multiple mycorrhizal inocula on growth of clover and strawberry plants at two soil pHs. Soil Biol Biochem 5, 539-544

Lin MT, Lucena FB, Mattos MAM, Paiva M, Assis M, Caldas LS (1987) Greenhouse production of mycorrhizal plants of nine transplanted crops. In: $M y$ corrhizae in the Next Decade, 7th NACOM (Sylvia DM, Hung LL, Graham JH, eds) Univ Florida, Gainesville, FL, 281

Phillips JM, Hayman DS (1970) Improved procedures for clearing roots and staining parasitic and vesicular-arbuscular mycorrhizal fungi for rapid assessment of infection. Trans BrMycol Soc 55, 158-161 